Article

\title{
Flotability Improvement of Ilmenite Using Attrition-Scrubbing as a Pretreatment Method
}

\author{
Jihua Zhai ${ }^{1}$, Pan Chen ${ }^{1, *}$, Hongbin Wang ${ }^{2}$, Yuehua Hu ${ }^{1}$ and Wei Sun ${ }^{1, *}$ \\ 1 School of Minerals Processing and Bioengineering, Central South University, Changsha 410083, China; \\ jihuazhai@csu.edu.cn (J.Z.); huyuehuacsu@126.com (Y.H.) \\ 2 Design and Research Institute of Panzhihua Iron and Steel Group Mining Co., Ltd., Panzhihua 617000, \\ China; whb7810@sohu.com \\ * Correspondence: panchen@csu.edu.cn (P.C.); sunmenghua@csu.edu.cn (W.S.)
}

Academic Editor: Massimiliano Zanin

Received: 17 November 2016; Accepted: 16 January 2017; Published: 22 January 2017

\begin{abstract}
Flotation technology of the recovery and utilization of ilmenite from tailings of iron beneficiated in Panzhihua was investigated based on mineralogical study. The results of mineralogical study show that the main occurrence of the valuable mineral are liberated grains of ilmenite. Experimental results of flotation conditions show that attrition-scrubbing raw ores exhibit good flotability with higher recoveries and a slight decrease in grade compared to ores without attrition-scrubbing. Further, open-circuit experiments also prove the superiority of attrition-scrubbing raw ores. The results of closed-circuit experiments show that qualified ilmenite concentrate can be obtained and the yield, grade, and recovery are $22.26 \%, 47.06 \%$, and $60.73 \%$, respectively. Theoretical study and analysis show that there are two contributions to superior flotability for attrition-scrubbing samples. The first is that the attrition-scrubbing samples can uncover more ferrous ions on the newly-produced fresh ilmenite surface, resulting in the increase in active sites. The other is that in the process of attrition-scrubbing, the transformation of ferrous ions to ferric ions can be promoted.
\end{abstract}

Keywords: attrition-scrubbing; ilmenite; high and efficient recovery

\section{Introduction}

Titanium and its alloy are widely studied with many advantages, such as corrosion resistance, higher strength to weight ratio, biocompatibility, and good temperature resistance [1-3]. Currently, it has been extensively applied in aerospace, medicine, navigation, and catalytic industries. Although abundant in the Earth's crust, titanium is still regarded as a rare metal because of the difficulties in extraction and its wide distribution [4]. Ilmenite and rutile are the main resources to beneficiation in $\mathrm{TiO}_{2}$ content for subsequent hydrometallurgy. Gravity separation, magnetic separation, and flotation are often combined to the separation of ilmenite and rutile from gangues [5]. For ilmenite, there are many pretreatment methods to improve its flotability, such as the surface dissolution method, oxidation roasting, microwave irradiation, and introducing ions. These pretreatment methods are collectively referred to as surface modification [6,7].

Tailings are generally considered as potential secondary resources with some valuable minerals to deep exploration and utilization [8]. Especially for those early tailings, some valuable minerals were abandoned because of the level limit of the original science and technology [9]. With the improvement in separation technology, those valuable minerals deposited in tailings can be utilized again using current science and technology. Due to the limitation of resources, it is urgent and meaningful to further recycle these valuable minerals. However, there are many difficulties during this period. Tailings usually have residual reagents and broad size distributions, resulting in separation difficulties using 
conventional methods [10]. Therefore, it is necessary to search for effective methods in separating valuable minerals from gangues.

Reagents play important roles in mineral selective flotation through adjusting the physicochemical properties of mineral particles. Environmentally-friendly reagents have attracted more attention and become a current tendency in froth flotation [11]. The effective recovery with little reagent dosages can reduce the impact of flotation reagents on environments, such as water quality. Fatty acids are generally used as collectors and fuel oils, such as diesel oils, are used as auxiliary collectors to enhance the recoveries of ilmenite as much as possible [12]. Additionally, phosphonic acids have been studied as collectors in ilmenite-selective flotation [13,14].

Panzhihua area possesses the largest deposit in vanadium-titanium magnetite with a high content in $\mathrm{MgO}[15,16]$. Generally, the circuit of ilmenite separation is behind the circuit of iron dressing. For iron dressing, the principal separation circuit is: low-intensity magnetic separation-classification-grinding-low-intensity magnetic separation. For ilmenite beneficiation, the frequently-used method is: low-intensity magnetic separation-spiral-high-intensity magnetic separation-flotation. The raw ores for ilmenite separation are usually tailings of iron beneficiation. With characteristics of $\mathrm{TiO}_{2}$ grade of $6.46 \%$ and $\mathrm{TFe}$ grade of $12.34 \%$, the early tailings of the Midi concentrating mill are investigated to recycle the valuable minerals. In the present study, the focus is on the ilmenite flotation separation process. Before the flotation, tailings were handled by low-intensity magnetic separation. The concentrate products were applied to recycled iron and the tailings were the raw minerals for ilmenite flotation. However, the grade of ilmenite was too low to meet the criteria for ilmenite flotation at present. Therefore, high-intensity magnetic separation was used to the pre-enrichment of ilmenite. After two high-intensity magnetic separations, the grade of $\mathrm{TiO}_{2}$ was approximately $17.2 \%$ and then the concentrate was used for ilmenite flotation. The purpose of the study is to improve the ilmenite flotability and seek measures for the effective recovery from tailings of iron beneficiation along with a higher grade.

\section{Experimental}

\subsection{Materials and Reagents}

The minerals throughout the experiments were tailings of iron beneficiation and obtained from the Panzhihua area of Sichuan Province in China. Industrial grade fatty acid salt was used as the collector and diesel oil was used as the assistant collector. Both fatty acid salt and diesel oil were provided by Nonferrous Metal Mineral Processing Reagent Co., Ltd., Panzhihua, China. Sulfuric acid was used as the $\mathrm{pH}$ modifier and purchased from Zhuzhou Chemical Industry Research Institute, Zhuzhou, China. Reagents used in the desulfurization process, such as xanthate and $2^{\#}$ oil, are also industrial grade and supplied by Mingzhu Mineral Processing Reagent Co., Ltd., Zhuzhou, China.

\subsection{Pre-Enrichment Methods}

The tailings of iron dressings have a low $\mathrm{TiO}_{2}$ grade of $6.33 \%$ and cannot meet the criteria for ilmenite flotation. Therefore, high-intensity magnetic separation was performed to obtain high-grade products for the following flotation. After one high-intensity magnetic separation, concentrate products with a $\mathrm{TiO}_{2}$ grade of $11.62 \%$ were obtained. To further pre-enrich the $\mathrm{TiO}_{2}$ grade, two high-intensity magnetic separation processes were required. Prior to the second high-intensity magnetic separation, liberation degree analysis for the concentrate products of one high-intensity magnetic separation was conducted and the results are shown in Table 1 . Table 1 shows that for +100 mesh samples, the liberation degree was below $80 \%$, showing that a grinding process was needed to further liberate ilmenite from gangues. For -100 mesh samples, the liberation degree was above $85 \%$. To reduce the harmful influence of overgrinding and save the production costs, there is no need to grind the -100 mesh samples. Classification results for concentrate products of one high-intensity magnetic separation showed that the yield of +100 mesh was $25.4 \%$. However, considering that ores are the early tailings of 
the Midi concentrating mill, the surfaces are seriously polluted during the process of emission and stockpiling. Therefore, the focus of the present study is on the comparison of attrition-scrubbing, or not, for -100 mesh samples. The principal flowchart is shown in Figure 1. When attrition-scrubbing was conducted, the products of two high-intensity magnetic separations were termed attrition-scrubbing samples. Correspondingly, the products were untreated samples when attrition-scrubbing was not carried out.

Table 1. The liberation degree analysis for the concentrate products of one high-intensity magnetic separation.

\begin{tabular}{cc}
\hline Particle Size/Mesh & Liberation Degree of Ilmenite (\%) \\
\hline+40 & 38.86 \\
+60 & 62.33 \\
+80 & 78.55 \\
+100 & 85.29 \\
+120 & 88.26 \\
+160 & 91.17 \\
+200 & 95.02 \\
-200 & 96.31 \\
\hline
\end{tabular}

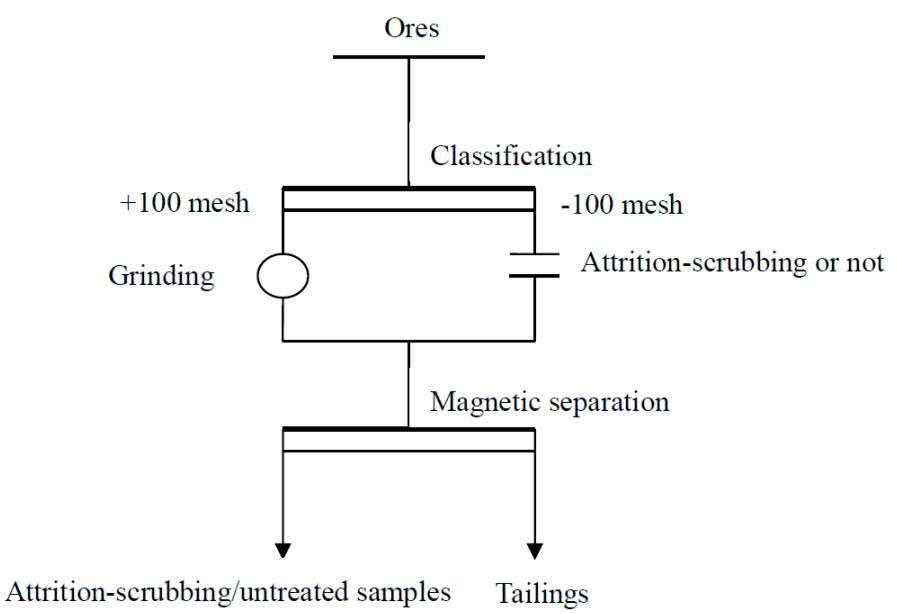

Figure 1. The principal flowchart of pre-enrichment for samples after one high-intensity magnetic separation.

\subsection{Attrition-Scrubbing Design}

Attrition-scrubbing tests were performed within glass mixing vessels. A mechanical overhead stirrer with a single axis and two bladed impeller was used in all attrition-scrubbing experiments. The impeller height was fixed and kept just above the bottom of the mixing vessel. The attrition-scrubbing procedures were as follows. First, a predetermined amount of sample was weighed and added to a mixing vessel. Then corresponding volume of water was poured to adjust the slurry. The impeller was down into the mixing vessel and then switched on. The attrition-scrubbing time was $25 \mathrm{~min}$ at a spindle speed of $1200 \mathrm{rpm}$ (revolutions per minute). During the process of attrition-scrubbing, the solid/liquid ratio was fixed at $65 \%$ and the $\mathrm{pH}$ environment was by nature, without any addition of acid and alkali. Additionally, the temperature was $25^{\circ} \mathrm{C}$ (room temperature). After attrition-scrubbing, the products were prepared for the second high-intensity magnetic separation.

\subsection{Characterization Methods}

The main chemical compositions of samples in experiments were characterized by the X-ray fluorescence spectrometry (XRF) technique using a Philips spectrometer. Microstructure of raw ore 
was characterized by optical microscopy (LEICADMLB, Leica, Welzlar, Germany). The products in all experiments were analyzed by XRF.

Attrition-scrubbing samples and untreated samples were prepared for analysis by an X-ray photoelectron spectrometer (XPS). During sampling, a population of particles were collected and sufficiently mixed. Prior to analysis, the samples were stored in liquid nitrogen to minimize oxidation. The XPS analyses were carried out using a Thermo Scientific ESCALAB 250Xi (Thermo Fisher Scientific, Waltham, MA, USA) instrument with an Al X-ray source operated at $200 \mathrm{~W}$. The vacuum pressure was ranged from $10^{-9}$ to $10^{-8}$ Torr, and the takeoff angle was $90^{\circ}$. The data were collected and processed using Thermo Scientific Avantage 4.52 software. The compositions of $\mathrm{Fe}^{3+}$ and $\mathrm{Fe}^{2+}$ are determined by the relative contents of the peak-fitting area. All binding energies were referenced to the neutral $\mathrm{C} 1 \mathrm{~s}$ peak at $284.8 \mathrm{eV}$ to compensate for the surface-charging effects.

\subsection{Experimental Procedure}

Flotation was conducted in a Denver laboratory sub-aeration cell. Rougher flotation was performed using a 1.5 L-capacity cell, whereas cleaner flotation was conducted with a 1 L-capacity cell. The flowchart of the flotation process is shown in Figure 2. The products were filtered, dried, weighed, and analyzed.

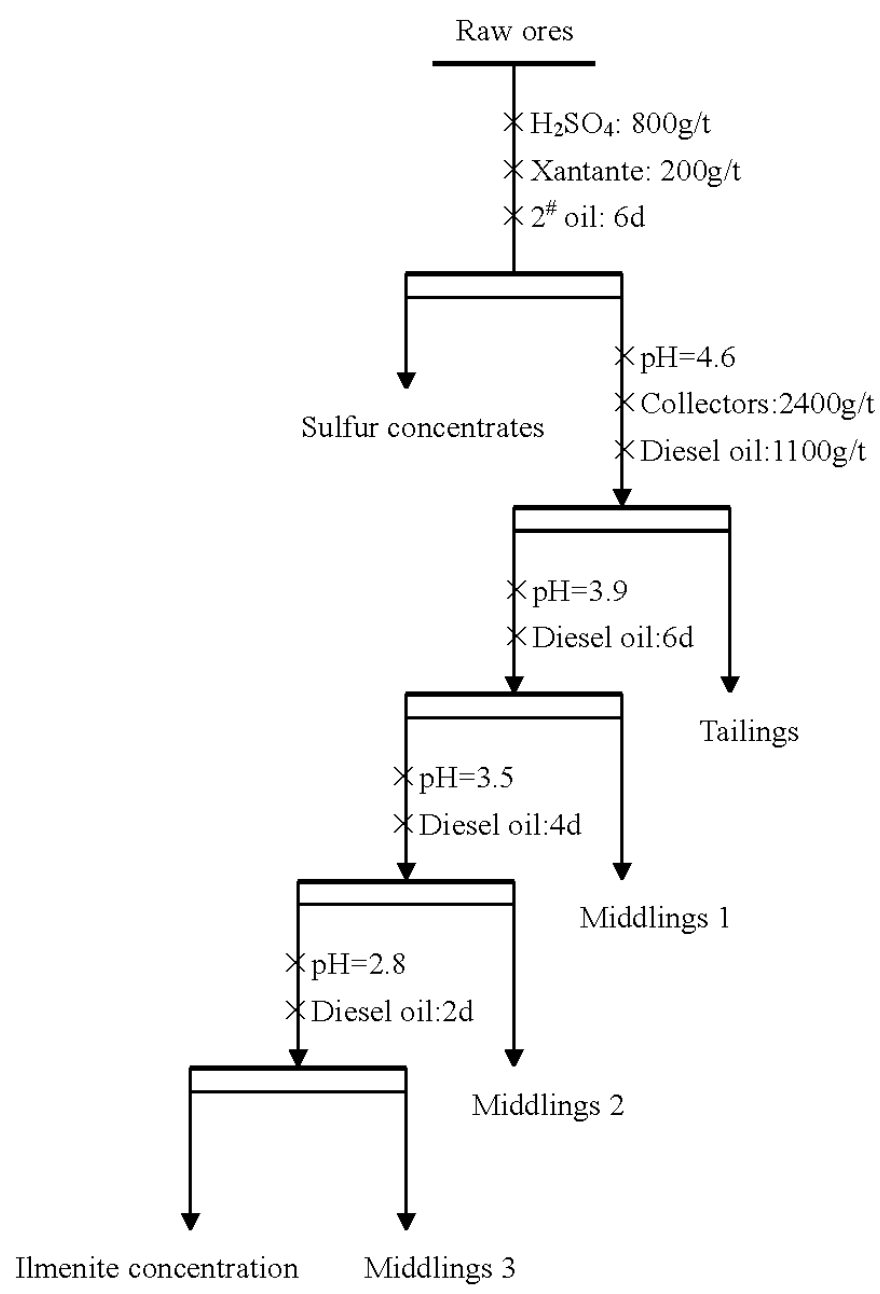

Figure 2. Principal flowchart for the ilmenite flotation experiments $\left(\mathrm{H}_{2} \mathrm{SO}_{4}\right.$ was used as $\mathrm{pH}$ modifier in the ilmenite flotation process). 


\section{Results and Discussions}

\subsection{Mineralogical Characteristics}

\subsubsection{Chemical Composition Analysis}

For raw ilmenite ores, it is important to ascertain the main chemical compositions to further confirm the possibility of utilization. The XRF measurements were carried out for raw ilmenite ores and the results are shown in Table 2. Based on Table 2, it can be determined that the chemical compositions of raw ilmenite ores are simple and the mainly valuable elements are titanium and iron, with contents of $17.23 \%$ and $19.43 \%$, respectively. The phase analyses results of iron and titanium given in Tables 3 and 4 show that the main phase of titanium is ilmenite with a content of $89.82 \%$. For iron, ilmenite is the main phase, along with $29.28 \%$ content of hematite.

Table 2. The main chemical compositions of the studied raw ilmenite ores (TFe: total Fe).

\begin{tabular}{lcccccccccc}
\hline Component & $\mathrm{TFe}$ & $\mathrm{TiO}_{2}$ & $\mathbf{V}_{\mathbf{2}} \mathrm{O}_{\mathbf{5}}$ & $\mathrm{SiO}_{\mathbf{2}}$ & $\mathrm{Al}_{\mathbf{2}} \mathrm{O}_{3}$ & $\mathrm{CaO}$ & $\mathbf{M g O}$ & $\mathbf{K}_{2} \mathrm{O}$ & $\mathbf{N a}_{2} \mathrm{O}$ & $\mathbf{S}$ \\
\hline Content $(\%)$ & 19.43 & 17.23 & 0.032 & 30.00 & 6.33 & 8.90 & 12.41 & 0.049 & 0.57 & 0.56 \\
\hline
\end{tabular}

Table 3. Phase analysis of iron (\%).

\begin{tabular}{cccccccc}
\hline Products & Iron Sulfide & Hematite & Titanomagnetite & Ilmenite & Carbonate Iron & Silicate Iron & Total \\
\hline Content & 0.02 & 5.69 & 0.99 & 9.41 & 0.81 & 2.51 & 19.43 \\
Distribution & 0.10 & 29.28 & 5.10 & 48.43 & 4.17 & 12.92 & 100.00 \\
\hline
\end{tabular}

Table 4. Phase analysis of titanium (\%).

\begin{tabular}{ccccc}
\hline Products & Titanomagnetite & Ilmenite & Sphene & Total $\left(\mathrm{TiO}_{\mathbf{2}}\right)$ \\
\hline Content & 0.70 & 15.48 & 1.05 & 17.23 \\
Distribution & 4.07 & 89.82 & 6.11 & 100.00 \\
\hline
\end{tabular}

\subsubsection{Occurrence of Ilmenite}

Based on the analysis shown in Section 3.1.1, ilmenite is the main titanium-containing mineral phase and the content can reach approximately $90 \%$. However, the embedded feature between valuable ilmenite and gangue seems to still be unclear. Therefore, the output characteristics of ilmenite were studied and the results are shown in Figure 3. It is clearly determined that ilmenite can be classified into two types, as follow: one is the liberated grains of ilmenite type, and the other is the type that ilmenite links with gangue or other minerals closely. For the former (shown in Figure 3a,b), the distribution of particles is even and the size range is approximately from 0.01 to $0.08 \mathrm{~mm}$. As for the latter (shown in Figure $3 c, d$ ), ilmenite exists in the form of intergrowth with gangue or hematite. As shown in Figure 3a, there are few sulfide minerals in the raw ore. Therefore, the desulphurization procedure before ilmenite flotation is necessary to produce qualified ilmenite concentrates. Systematic mineralogical study shows that the proportion of the liberated grains of ilmenite to intergrowth ilmenite is 90:10. Hence, the liberated grains of the ilmenite type is the primary object for recovering. 

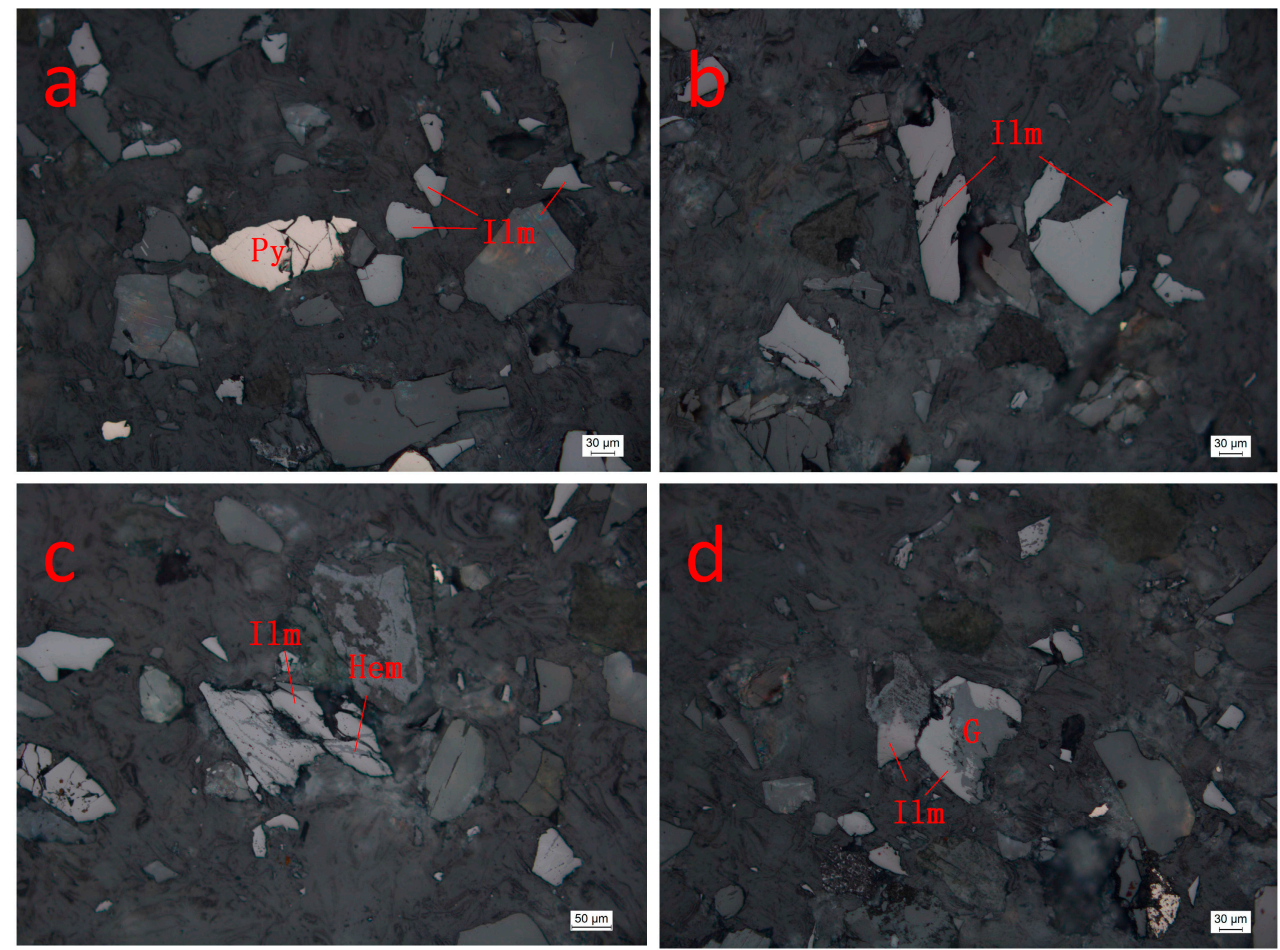

Figure 3. Optical micrographs of raw ilmenite ore samples: (a) liberated grains of ilmenite with little pyrite; (b) liberated grains of ilmenite; (c) ilmenite closely linked with hematite; (d) ilmenite closely linked with other gangues (Ilm: ilmenite; Hem: hematite; Py: pyrite; G: gangue).

\subsubsection{Ilmenite Distribution in Ore Samples}

Attrition-scrubbing samples and untreated samples were classified to study the distribution of ilmenite in different grain sizes. The results of classification are shown in Tables 5 and 6 for untreated and attrition-scrubbing samples, respectively. It can be seen that whether attrition-scrubbing or not, the ilmenite distribution in ore samples was similar. For untreated and attrition-scrubbing samples, $-0.074 \mathrm{~mm}$ fractions had total proportions of $63.08 \%$ and $63.86 \%$, respectively. Additionally, attrition-scrubbing, as a pretreatment method, does not have obvious influence on ilmenite distribution in different grain sizes.

Table 5. Ilmenite distribution in untreated samples.

\begin{tabular}{ccccc}
\hline Products & Grain Size (mm) & Yield (\%) & Grade (\%) & Distribution (\%) \\
\hline & +0.25 & 1.14 & 9.75 & 0.65 \\
+0.18 & 2.27 & 13.86 & 1.83 \\
+0.154 & 2.99 & 14.86 & 2.58 \\
Untreated Samples & +0.125 & 11.56 & 16.03 & 10.77 \\
& +0.098 & 14.34 & 15.75 & 13.13 \\
& +0.074 & 9.29 & 14.74 & 7.96 \\
& +0.045 & 22.6 & 15.65 & 20.56 \\
& +0.038 & 4.75 & 17.87 & 4.92 \\
& -0.038 & 31.06 & 20.83 & 37.6 \\
& $\sum$ & 100 & 17.21 & 100 \\
\hline
\end{tabular}


Table 6. Ilmenite distribution in attrition-scrubbing samples.

\begin{tabular}{ccccc}
\hline Products & Grain Size (mm) & Yield (\%) & Grade (\%) & Distribution (\%) \\
\hline & +0.25 & 1.21 & 9.83 & 0.69 \\
& +0.18 & 2.34 & 13.85 & 1.88 \\
& +0.154 & 3.05 & 14.93 & 2.64 \\
Attrition-scrubbing samples & +0.125 & 10.84 & 15.76 & 9.92 \\
& +0.098 & 14.15 & 15.82 & 12.99 \\
& +0.074 & 9.34 & 14.79 & 8.02 \\
& +0.045 & 22.87 & 15.68 & 20.81 \\
& +0.038 & 4.82 & 17.92 & 5.01 \\
& -0.038 & 31.38 & 20.87 & 38.04 \\
& $\sum$ & 100 & 17.23 & 100.00 \\
\hline
\end{tabular}

\subsection{Flotation Results and Analysis}

\subsubsection{Flotation Condition Tests}

To ensure that the process of ilmenite flotation can be conducted efficiently, the flotation condition tests were carried out firstly. $\mathrm{H}_{2} \mathrm{SO}_{4}$ is usually used as the $\mathrm{pH}$ modifier in ilmenite flotation because it can absorb on the ilmenite surface specially and promote its flotability, in addition to the $\mathrm{pH}$ adjustment function [17]. Therefore, the experiments of sulfuric acid dosage were conducted under the condition that the dosages of the collector and diesel oil were 2200 and $1100 \mathrm{~g} / \mathrm{t}$, respectively, and the results are illustrated in Figure 4. As shown in Figure 4, whether attrition-scrubbing or not, the grade of rough concentrate increases with the dosage of sulfuric acid and the recovery reverses correspondingly. Compared to samples without attrition-scrubbing using the same dosage of sulfuric acid, the recoveries of attrition-scrubbing samples are higher with little decrease in grade and the recovery increase can reach approximately $3 \%$. Thus, it is determined that attrition-scrubbing samples are superior and are beneficial to ilmenite flotation. To obtain a higher recovery and suitable grade, comprehensively, the optimum dosage of sulfuric acid is $1400 \mathrm{~g} / \mathrm{t}$ and, at present for attrition-scrubbing samples, a rough concentrate with a grade of $33.51 \%$ and recovery of $77.95 \%$ can be produced through one roughing. The $\mathrm{pH}$ value is approximately 4.6 using the optimum $1400 \mathrm{~g} / \mathrm{t}$ dosage of sulfuric acid.

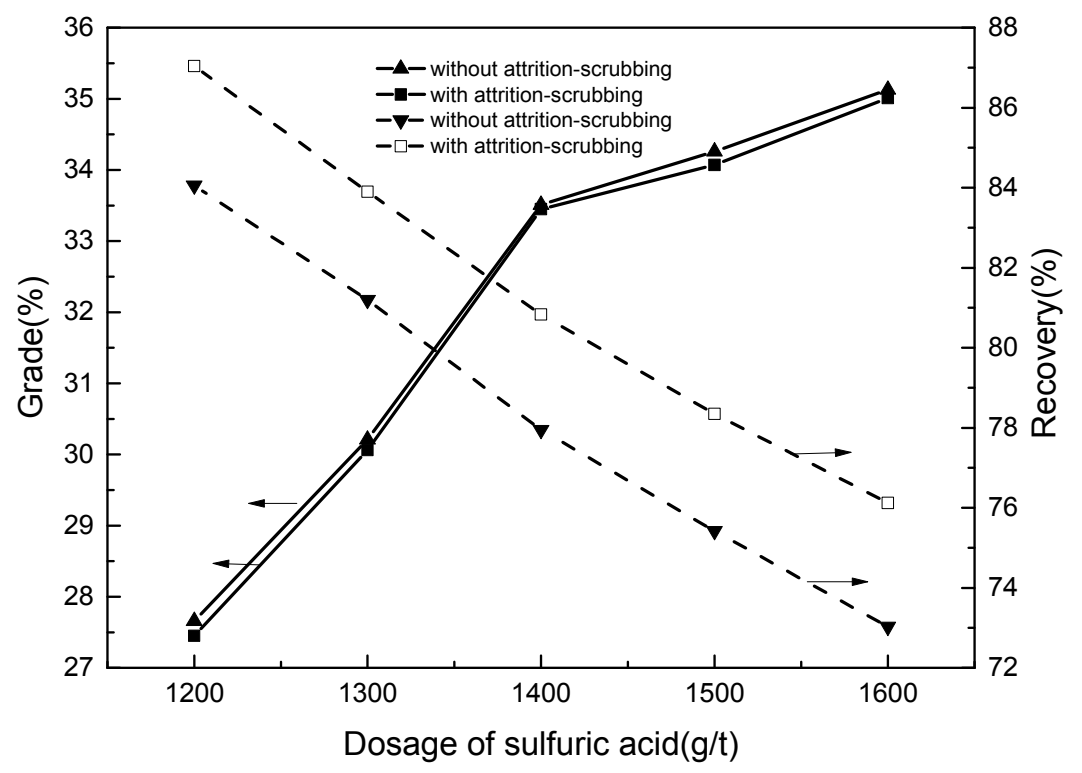

Figure 4. The results of sulfuric acid dosage on the flotation behaviors of ilmenite. 
After the tests of sulfuric acid dosage, the experiments of collector dosage were carried out and the results are shown in Figure 5. It is well known to us all that the collector dosage has a vital influence on the grade and recovery of concentrate. In the process, the dosages of sulfuric acid and diesel oil were 1400 and $1100 \mathrm{~g} / \mathrm{t}$, respectively. The results show the same superiority for attrition-scrubbing samples compared to those without attrition-scrubbing, which is similar to the tests of the sulfuric acid dosage. With the increase of the collector dosage, the grade of rough concentrate decreases slightly, while the recovery increases obviously. After a comprehensive consideration, the optimum dosage of the collector is $2400 \mathrm{~g} / \mathrm{t}$ and a rough concentrate can be obtained with the grade of $31.92 \%$ and recovery of $80.88 \%$.

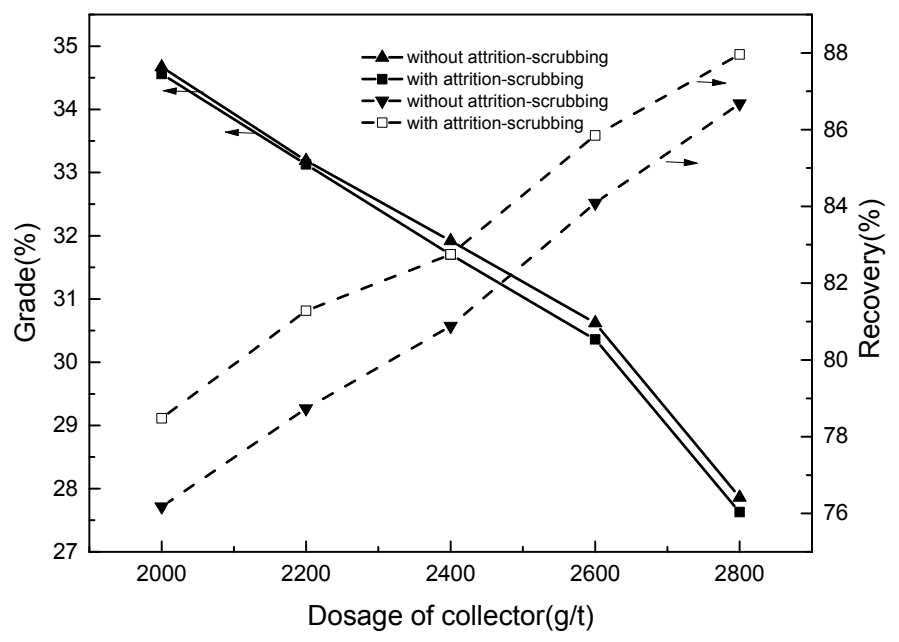

Figure 5. The results of the collector dosage on the flotation behaviors of ilmenite.

In the process of ilmenite separation, diesel oil is often used as an auxiliary collector to increase the recovery of ilmenite concentrate. The experiments of diesel oil dosage were conducted under the circumstance that dosages of sulfuric acid and the collector were 1400 and $2400 \mathrm{~g} / \mathrm{t}$, and the results are shown in Figure 6. The influence of diesel oil dosage resembles the effects of the collector on the flotation behavior of raw ilmenite ore. Similarly, the superiority of attrition-scrubbing samples is present in the experiments of diesel oil dosage.

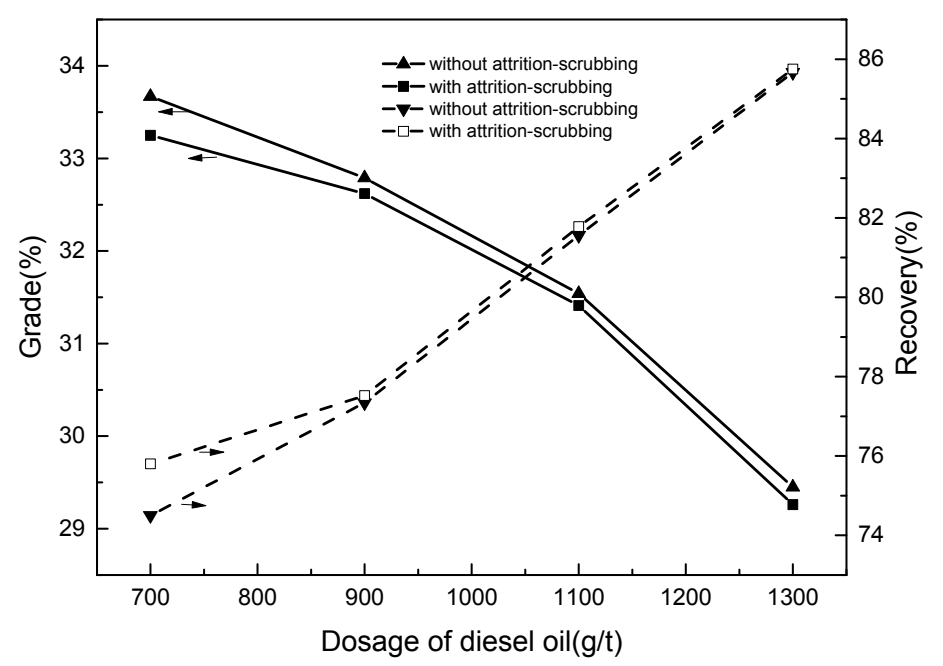

Figure 6. The results of diesel oil dosage on the flotation behaviors of ilmenite. 


\subsubsection{Open-Circuit Contrast Tests}

The results of flotation condition tests above all show the superiority of attrition-scrubbing samples compared to those without attrition-scrubbing in the process of ilmenite flotation. That is to say that attrition-scrubbing samples have an obvious increase in recovery and almost no influence on concentrate grade. To further verify the phenomenon, open-circuit contrast tests were carried out and the results are shown in Tables 7 and 8. From Table 7 to Table 8, it is shown that ilmenite concentrate with the grade of $47.31 \%$ and recovery of $47.64 \%$ can be produced for samples without attrition-scrubbing through one roughing and three cleanings. For attrition-scrubbing samples treated with the same circuit, ilmenite concentrate can be produced with the grade of $47.21 \%$ and recovery of $55.16 \%$. By comparison, attrition-scrubbing samples can increase the recovery by $7.52 \%$ and a slight decrease in grade by $0.1 \%$. These results suggest that after attrition-scrubbing, ilmenite can interact with the collector more strongly and consistently. Therefore, attrition-scrubbing, as a pretreatment method, can realize the effective recovery and utilization of ilmenite.

Table 7. The results of open-circuit test of samples without attrition-scrubbing.

\begin{tabular}{cccc}
\hline Product & Yield (\%) & Grade (\%) & Recovery (\%) \\
\hline Sulfur concentrate & 5.09 & 10.53 & 3.12 \\
Concentrate & 17.32 & 47.31 & 47.64 \\
Middling 1 & 12.12 & 15.62 & 11.01 \\
Middling 2 & 7.56 & 24.37 & 10.71 \\
Middling 3 & 5.01 & 34.51 & 10.05 \\
Tailing & 52.9 & 5.68 & 17.47 \\
Raw ore & 100 & 17.2 & 100 \\
\hline
\end{tabular}

Table 8. The results of open-circuit test of attrition-scrubbing samples.

\begin{tabular}{cccc}
\hline Product & Yield (\%) & Grade (\%) & Recovery (\%) \\
\hline Sulfur concentrate & 5.24 & 10.47 & 3.18 \\
Concentrate & 20.13 & 47.21 & 55.16 \\
Middling 1 & 9.12 & 17.01 & 9 \\
Middling 2 & 6.26 & 23.88 & 8.68 \\
Middling 3 & 3.86 & 32.65 & 7.31 \\
Tailing & 55.39 & 5.18 & 16.67 \\
Raw ore & 100 & 17.23 & 100 \\
\hline
\end{tabular}

\subsubsection{Closed-Circuit Test}

Compared to the results of flotation condition tests, the results of open-circuit tests further show the significance of attrition-scrubbing, as a pretreatment method. Therefore, for attrition-scrubbing samples, the closed-circuit test was investigated and the results are shown in Table 9. In the process of the closed-circuit test, the middlings were returned in order. The results show that a qualified ilmenite concentrate can be produced with the grade of $47.06 \%$ and recovery of $60.73 \%$. The flotation indices are good and the effective recovery of ilmenite can be realized.

Table 9. The results of closed-circuit test of attrition-scrubbing samples.

\begin{tabular}{cccc}
\hline Product & Yield (\%) & Grade (\%) & Recovery (\%) \\
\hline Sulfur concentrate & 5.39 & 10.28 & 3.21 \\
Concentrate & 22.26 & 47.06 & 60.73 \\
Tailing & 72.35 & 8.60 & 36.06 \\
Raw ore & 100 & 17.25 & 100 \\
\hline
\end{tabular}




\subsection{Discussions}

As shown in the results of flotation experiments, attrition-scrubbing can improve the flotability of raw ilmenite samples. Therefore, it is essential to explore the mechanism during this period. Based on previous studies [12,18], the speciation of the ilmenite surface as a function of the solution's $\mathrm{pH}$ is modified and shown in Figure 7. As illustrated in Figure 7, the main active sites are titanium ions and a series of its hydroxyl complexes in strongly acidic environments. During the process of cleaning, relative $\mathrm{pH}$ values are $3.9,3.5$, and 2.8 , for three cleaning states. It is determined that titanium ions and a series of its hydroxyl complexes make critical contributions to the ilmenite cleaning states. When the $\mathrm{pH}$ is above 4, iron ions and its hydroxyl complex begin to turn into the main active sites. Within the best $\mathrm{pH}$ range for ilmenite rough flotation $\left(\mathrm{pH}=4.6\right.$ or $\mathrm{H}_{2} \mathrm{SO}_{4}$ dosage $\left.=1400 \mathrm{~g} / \mathrm{t}\right)$, the mainly functional active sites are iron ions and its hydroxyl complex. It is widely known that attrition-scrubbing, as a pretreatment method, can remove slimes or impurities on samples' surfaces and produce a fresh surface on the raw ilmenite samples, resulting in greater exposure of active sites $[19,20]$. Herein, this is one reason for the improvement of ilmenite flotability and an increase in recovery. Studies also show that, as for ilmenite, the content of $\mathrm{Fe}^{3+}$ on the ilmenite surface has an obvious influence on the ilmenite flotation because the solubility product constant $\left(\mathrm{K}_{\mathrm{sp}}\right)$ of $\mathrm{Fe}^{3+}$ is smaller than that of $\mathrm{Fe}^{2+}$, suggesting that $\mathrm{Fe}(\mathrm{OL})_{3}$ products are more stable and $\mathrm{Fe}^{3+}$ is more inclined to interact with the collector rather than $\mathrm{Fe}^{2+}$ [21]. During the process of attrition-scrubbing, a fresh surface is produced with a characteristic of high-activity and, because of the oxidation, the conversion trend of $\mathrm{Fe}^{3+}$ to $\mathrm{Fe}^{2+}$ is augmented. In order to further confirm this possibility, XPS tests for attrition-scrubbing samples and samples without attrition-scrubbing were carried out and the results analyzed by peak-fitting are shown in Figure 8. Furthermore, the results of valence states and contents of iron elements before and after attrition-scrubbing are shown in Table 10. During the process of peak-fitting, peaks at 710.5 and $712.5 \mathrm{eV}$ are characteristic peaks [22,23] for $\mathrm{Fe}(\mathrm{II})$ and $\mathrm{Fe}(\mathrm{III})$, respectively. The peak-fitting error is $\pm 0.2 \mathrm{eV}$ within the standard error range. As shown in Table 10, for samples without attrition-scrubbing, the contents of $\mathrm{Fe}^{3+}$ and $\mathrm{Fe}^{2+}$ are $18.67 \%$ and $81.33 \%$, respectively. After attrition-scrubbing, the content of $\mathrm{Fe}^{3+}$ is $29.63 \%$ and the increase is $10.96 \%$ compared to samples without attrition-scrubbing. The increase in $\mathrm{Fe}^{3+}$ content on the ilmenite surface can promote ilmenite flotability because of the important role of $\mathrm{Fe}^{3+}$ in ilmenite flotation. Systematic mineralogical studies show that the main recovering object for $\mathrm{TiO}_{2}$ are liberated grains of ilmenite $(90 \%)$. The $10 \%$ proportion of intergrowth ilmenite cannot be easily recovered except through further regrinding, which may cause over-grinding and increase the difficulties in fine ilmenite flotation. For attrition-scrubbing samples, if the increasing proportion of $\mathrm{Fe}^{3+} / \mathrm{Fe}^{2+}$ was mainly caused by hematite exposure, the $\mathrm{TiO}_{2}$ recovery should not have increased so much. Furthermore, during processes of attrition-scrubbing and magnetic separation, the pulp was not adjusted by $\mathrm{H}_{2} \mathrm{SO}_{4}$. Therefore, the dissolution of iron is slight during the pre-enrichment process and the effect of re-adsorption of dissolved iron ions on the XPS measurement results can be neglected. Consequently, the increase in $\mathrm{Fe}^{3+}$ content on the ilmenite surface is another reason for the improvement in ilmenite flotation.

Table 10. The results of valence states and contents of iron elements before and after attrition-scrubbing.

\begin{tabular}{ccccc}
\hline \multirow{2}{*}{ Sample } & \multicolumn{2}{c}{ Binding Energy (eV) } & \multicolumn{2}{c}{ Percentage in Total Fe (\%) } \\
\cline { 2 - 5 } & $\mathbf{F e}^{\text {2+ } / \text { Peak } \mathbf{1}}$ & $\mathbf{F e}^{\text {3+/Peak } \mathbf{2}}$ & $\mathbf{F e}^{\mathbf{2 +} / \text { Peak 1 }}$ & $\mathbf{F e}^{\mathbf{3 +} / \text { Peak 2 }}$ \\
\hline Without attrition-scrubbing & 710.5 & 712.5 & 81.33 & 18.67 \\
With attrition-scrubbing & 710.4 & 712.3 & 70.37 & 29.63 \\
\hline
\end{tabular}




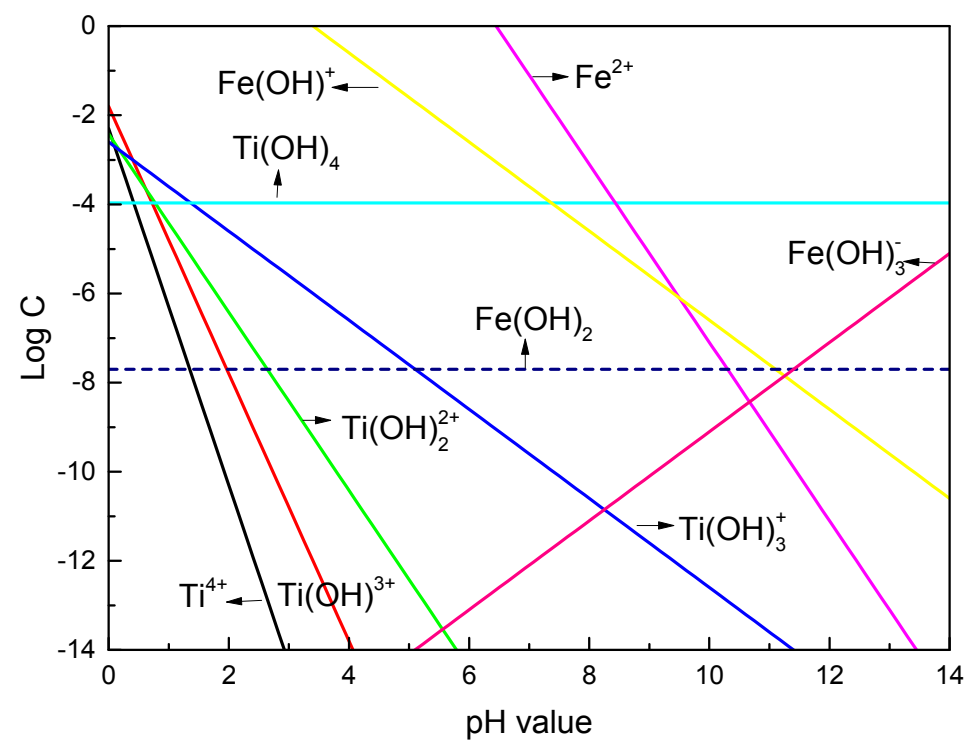

Figure 7. The speciation of the ilmenite surface as a function of solution $\mathrm{pH}$ (modified from [12]).
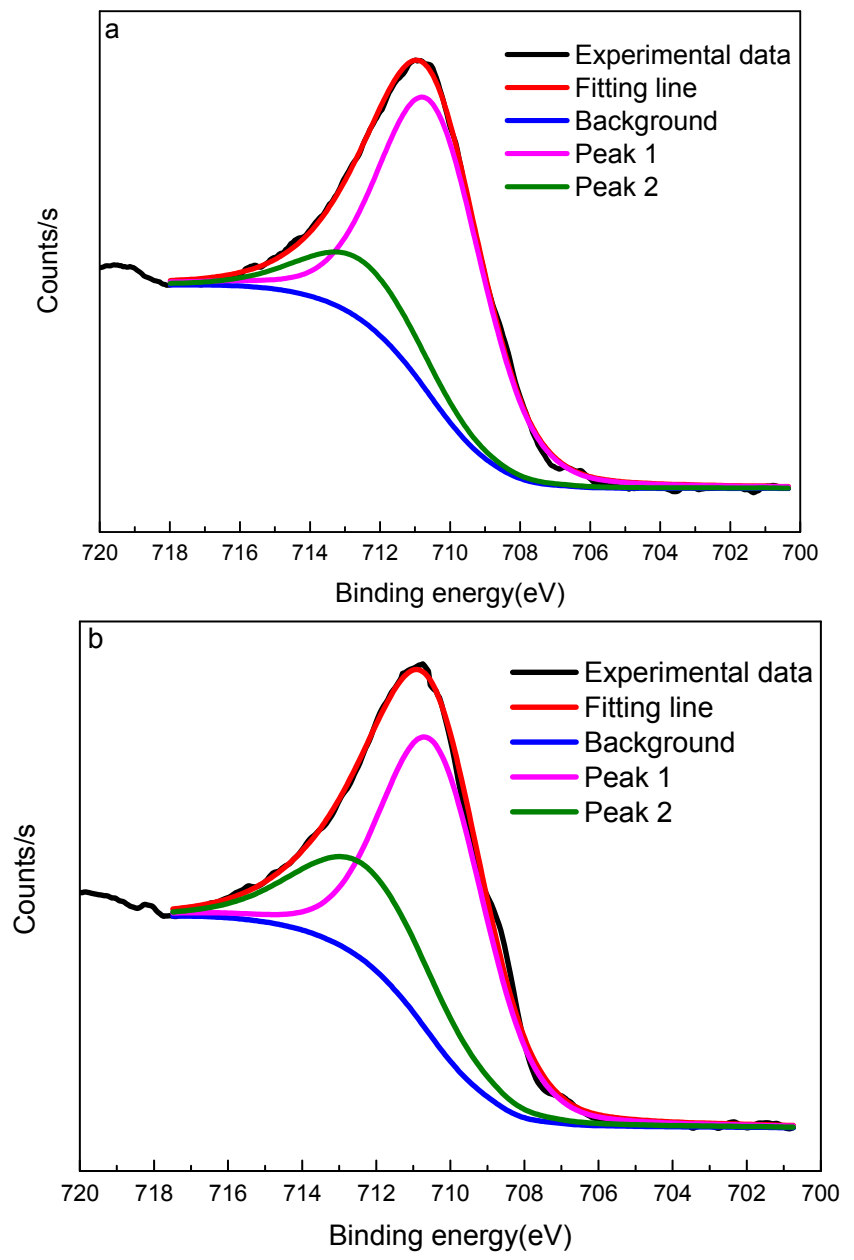

Figure 8. The results of X-ray photoelectron spectrometer (XPS) tests for raw ilmenite ore: (a) samples without attrition-scrubbing; (b) attrition-scrubbing samples. 


\section{Conclusions}

Based on the results of mineralogic studies, flotation tests, and the discussions above, the following conclusion can be drawn:

(1) The main phase of valuable titanium is ilmenite, which is present in the form of liberated grains of ilmenite and is the primary object for recovering;

(2) During the optimization process of flotation conditions, compared to samples without attrition-scrubbing, attrition-scrubbing samples have superiority with respect to the effective flotation recovery of ilmenite. The results of open-circuit contrast tests further show that attrition-scrubbing can obtain a concentration with higher recovery and a slight decrease in grade. The results of closed-circuit tests show that a qualified concentrate with the grade of $47.06 \%$ and recovery of $60.73 \%$ can be produced. The better recovery and utilization of ilmenite can be realized; and

(3) After discussions, the reasons for the improvement in ilmenite flotability after treatment with attrition-scrubbing are as follows: one is that a fresh surface with more exposed active sites can be produced after attrition-scrubbing; the other is that during the process of attrition-scrubbing, some $\mathrm{Fe}(\mathrm{II})$ can convert into $\mathrm{Fe}(\mathrm{III})$ and this makes another critical contribution to the improvement in ilmenite flotation.

Acknowledgments: The authors acknowledge the support of the national science and technology support program (2015BAB19B01), the Innovation-driven Program of Central South University of China (2015CX005), the National 111 Project (B14034), the National Natural Science Foundation of China (51504290) and the Collaborative Innovation Center for Clean and Efficient utilization of Strategic Metal Mineral Resources.

Author Contributions: Pan Chen, Yuehua Hu and Wei Sun conceived and designed the experiments; Jihua Zhai, Hongbin Wang and Pan Chen performed the experiments and analyzed the date; Pan Chen, Hongbin Wang and Wei Sun contributed reagents and materials; Jihua Zhai and Pan Chen wrote the paper.

Conflicts of Interest: The authors declare no conflict of interest.

\section{References}

1. Zorn, G.; Gotman, I.; Gutmanas, E.Y.; Adadi, R.; Salitra, G.; Sukenik, C.N. Surface modification of Ti45Nb alloy with an alkylphosphonic acid self-assembled monolayer. Chem. Mater. 2005, 17, 4218-4226. [CrossRef]

2. Foster, T.T.; Alexander, M.R.; Leggett, G.J.; McAlpine, E. Friction force microscopy of alkylphosphonic acid and carboxylic acids adsorbed on the native oxide of aluminum. Langmuir 2006, 22, 9254-9259. [CrossRef] [PubMed]

3. Quiñones, R.; Raman, A.; Gawalt, E.S. Functionalization of nickel oxide using alkylphosphonic acid self-assembled monolayers. Thin Solid Films 2008, 516, 8774-8781. [CrossRef]

4. Wang, S.; Li, J.; Wu, S.; Yan, W.; Huang, W.X.; Miao, L.; Chen, Z. The distribution characteristics of rare metal elements in surface sediments from four coastal bays on the northwestern South China Sea. Estuar. Coast. Shelf Sci. 2015, 169, 106-118. [CrossRef]

5. Zhu, Y.; Zhang, G.; Feng, Q.; Yan, D.C.; Wang, W.Q. Effect of surface dissolution on flotation separation of fine ilmenite from titanaugite. Trans. Nonferr. Met. Soc. China 2011, 21, 1149-1154. [CrossRef]

6. Cutmore, N.; Evans, T.; Crnokrak, D.; Middleton, A.; Stoddard, S. Microwave technique for analysis of mineral sands. Miner. Eng. 2000, 13, 729-736. [CrossRef]

7. Zhang, G.; Ostrovski, O. Effect of preoxidation and sintering on properties of ilmenite concentrates. Int. J. Miner. Process. 2002, 64, 201-218. [CrossRef]

8. Bryan, C.G.; Hallberg, K.B.; Johnson, D.B. Mobilisation of metals in mineral tailings at the abandoned São Domingos copper mine (Portugal) by indigenous acidophilic bacteria. Hydrometallurgy 2006, 83, 184-194. [CrossRef]

9. Morin, D.H.R.; D'Hugues, P. Bioleaching of a Cobalt-Containing Pyrite in Stirred Reactors: A Case Study from Laboratory Scale to Industrial Application. In Biomining; Springer: Berlin, Germany, 2007; pp. 35-55.

10. Lottermoser, B.G. Recycling, Reuse and Rehabilitation of Mine Wastes. Elements 2011, 7, 405-410. [CrossRef] 
11. Sarquís, P.E.; Menéndez-Aguado, J.M.; Mahamud, M.M.; Dzioba, R. Tannins: The organic depressants alternative in selective flotation of sulfides. J. Clean. Prod. 2014, 84, 723-726. [CrossRef]

12. Fan, X.; Waters, K.E.; Rowson, N.A.; Paker, D.J. Modification of ilmenite surface chemistry for enhancing surfactants adsorption and bubble attachment. J. Colloid Interface Sci. 2009, 329, 167-172. [CrossRef] [PubMed]

13. Bulatovic, S.; Wyslouzil, D.M. Process development for treatment of complex perovskite, ilmenite and rutile ores. Miner. Eng. 1999, 12, 1407-1417. [CrossRef]

14. Li, F.; Zhong, H.; Wang, S.; Liu, G.Y. The activation mechanism of $\mathrm{Cu}(\mathrm{II})$ to ilmenite and subsequent flotation response to $\alpha$-hydroxyoctyl phosphinic acid. J. Ind. Eng. Chem. 2016, 37, 123-130. [CrossRef]

15. Zhou, M.F.; Chen, W.T.; Wang, C.Y.; Prevec, S.A.; Liu, P.P.P.; Howarth, G.H. Two stages of immiscible liquid separation in the formation of Panzhihua-type Fe-Ti-V oxide deposits, SW China. Geosci. Front. 2013, 4, 481-502. [CrossRef]

16. Zhao, J.H.; Zhou, M.F. Geochemistry of Neoproterozoic mafic intrusions in the Panzhihua district (Sichuan Province, SW China): Implications for subduction-related metasomatism in the upper mantle. Precambr. Res. 2007, 152, 27-47. [CrossRef]

17. Welham, N.J.; Llewellyn, D.J. Mechanical enhancement of the dissolution of ilmenite. Miner. Eng. 1998, 11, 827-841. [CrossRef]

18. Mehdilo, A.; Irannajad, M.; Rezai, B. Effect of crystal chemistry and surface properties on ilmenite flotation behavior. Int. J. Miner. Process. 2015, 137, 71-81. [CrossRef]

19. Bayley, R.W.; Biggs, C.A. Characterisation of an attrition scrubber for the removal of high molecular weight contaminants in sand. Chem. Eng. J. 2005, 111, 71-79. [CrossRef]

20. Petavy, F.; Ruban, V.; Conil, P. Treatment of stormwater sediments: Efficiency of an attrition scrubberlaboratory and pilot-scale studies. Chem. Eng. J. 2009, 145, 475-482. [CrossRef]

21. Zhong, K.; Cui, L. Influence of $\mathrm{Fe}^{2+}$ ions of ilmenite on its flotability. Int. J. Miner. Process. 1987, $20,253-265$. [CrossRef]

22. Irannajad, M.; Mehdilo, A.; Nuri, O.S. Influence of microwave irradiation on ilmenite flotation behavior in the presence of different gangue minerals. Sep. Purif. Technol. 2014, 132, 401-412. [CrossRef]

23. Mehdilo, A.; Irannajad, M. Comparison of microwave irradiation and oxidation roasting as pretreatment methods for modification of ilmenite physicochemical properties. J. Ind. Eng. Chem. 2015, 33, 59-72. [CrossRef]

(C) 2017 by the authors; licensee MDPI, Basel, Switzerland. This article is an open access article distributed under the terms and conditions of the Creative Commons Attribution (CC BY) license (http:/ / creativecommons.org/licenses/by/4.0/). 